Irina $\boldsymbol{V}$. Kupriianova,

Dr. of Historical Sciences, Associate Professor, Altai State Institute of Culture (Barnaul, Russia) irinak-63@mail.ru

\title{
COMMERCIALIZATION OF OLD BELIEVERS' CULTURAL HERITAGE IN TOURISTIC CLUSTER OF THE UYMON VALLEY (REPUBLIC OF ALTAI, RUSSIA)
}

\begin{abstract}
The article analyses an experience of integration of material and intangible cultural heritage objects of Old Believers from the Uymon Valley (the Altai Republic, Russia) into the hotel and touristic sector of the region.

On the author's opinion, unique natural settings of the territory provide its status as an object of mass tourism; local habitants try to satisfy increasing demand on goods and services "with local charm" and make business that almost absolutely focuses on old-time techniques of husbandry adapted to the modernity, peasant archaic architecture, artifacts of traditional culture of Old Believers from the Uymon Valley.

Key words: the Uymon Valley, Old Believers from the Uymon Valley, Old Belief's cultural heritage, Nicholas Roerich, touristic service, the Altai Republic (Russia), architecture of Old Believers from the Uymon Valley, museums of Old Belief.
\end{abstract}

УДК 069-052-057.75:316.4.051.63:316.7

DOI 10.32340/2414-9101-2020-2-35-40

Е. Н. Мастеница,

кандидат исторических наук, доцент, Санкт-Петербургский государственный институт культуры (Санкт-Петербург, Россия) elenamast@yandex.ru

\section{МЕЖПОКОЛЕННАЯ КОММУНИКАЦИЯ В МУЗЕЕ КАК ФАКТОР СОХРАНЕНИЯ И ТРАНСЛЯЦИИ КУЛЬТУРНОГО НАСЛЕДИЯ}

Аннотация. Представлена обзорная характеристика основных направлений работы современного российского музейного учреждения с категорией посетителей старше 60 лет (пенсионного возраста), доля которых в составе совокупной музейной аудитории демонстрирует устойчивый динамичный рост. Названы некоторые варианты ролевого статуса лиц пожилого возраста, выступающих в качестве активных субъектов музейной коммуникации. Автор статьи на конкретных примерах анализирует содержание наиболее распространённых форм субъект-объектного взаимодействия (с участием представителей социально-демографической категории пожилых людей) в рамках музейной коммуникации: научно-экспозиционной интерпретации, форм культурнообразовательной деятельности, синтетической формы вербально-визуальной трансляции, комплексной формы трансляции наследия.

Ключевые слова: культурное наследие, музей, актуализация культурного наследия в музее, трансляция культурного наследия в музее, музейньй посетитель «серебряного возраста», пожилой посетитель музея, межпоколенная музейная коммуникация, ресоциализация лии пенсионного возраста средствами музейной работы.

Одним из главных вызовов современности, с которым сталкивается человечество, это необходимость сочетать новые способы жизни и инновационного развития с интересами сохранения культурного и природного наследия. Переход к устойчивому развитию общества требует новых способов мышления и норм поведения. Музеи играют ключевую роль в этом переходе. Именно они не только обеспечивают устойчивое развитие, но и служат своеобразными социокультурными лабораториями для проверки лучших практик. Современные музеи вне зависимости от масштаба, 
профиля и места расположения должны занять твёрдую позицию в связи с этими процессами и приложить все усилия, чтобы общество и власть услышало их голос. Призывая музеи выдвинуться на передовую линию построения модели устойчивого развития общества и формирования качественной культурной среды, мы ставим своей целью обратиться к рассмотрению такого малоизученного аспекта, как взаимодействие с людьми «серебряного возраста». Современное музейное учреждение уделяет повышенное внимание категориям социально незащищённых слоёв населения, в связи с чем актуальным становится привлечение в музей людей «серебряного возраста», число которых в России стремительно растёт.

В музеях нашей страны ещё не появились специальные отделы по работе с данным сегментом музейной аудитории, не разработана методическая база и не сложилось представление о том, как выстроить долговременные контакты с пожилыми людьми в музее. Однако, новые формы, программы и проекты, которые пока единичны в музеях, по взаимодействию с этими посетителями свидетельствует о том, что есть стремление изменить ситуацию.

Категория пожилых людей ещё не слишком востребована в российских музеях, многие из них не спешат адресно обращаться к этой части музейной аудитории и не знают, что могут получить от неё взамен. Однако, сотрудничество музея с людьми «серебряного возраста» может стать двусторонним процессом, а пожилой посетитель рассматриваться не только в качестве объекта, но и в качестве субъекта этого взаимодействия. Представители старших возрастов, как свидетели прошлого и носители наследия, могут выступать в качестве экспертов, консультантов, информаторов, волонтёров, помощников музея в процессах комплектования, актуализации и трансляции наследия. Музей как социокультурный институт обладает большим потенциалом для оказания помощи этой категории посетителей в решении проблем ресоциализации, что будет способствовать возрастанию уровня социального благополучия и качества культурной среды города или региона в целом.

Актуализация и трансляция культурного наследия тесно связаны друг с другом и реализуются именно в музее, деятельность которого направлена на сохранение и популяризацию наследия. В словаре актуальных музейных терминов понятие «актуализация наследия» объяснено как «деятельность, направленная на сохранение и включение культурного и природного наследия в современную культуру путём активизации социокультурной роли его объектов и их интерпретации» [1, с. 49]. Понятие «трансляция наследия» трактуется как «передача накопленного человечеством опыта (за счёт «хранения, комплектования, учёта, изучения и популяризации памятников истории и культуры, а также природных объектов»)» [2, с. 85].

В работе Ю. А. Прокопенко мы встречаем иное определение: «трансляция - общение, направленное на социализацию входящих в жизнь поколений, на их уподобление старшим средствами соответствующих институтов и механизмов. $<\ldots>$ Одной стороне - действующей от имени общества, а практически от имени одного из фрагментов социокода, воспитателям нужно передать другой стороне - воспитуемым - то, чем эта другая сторона не располагает: установившиеся нормы деятельности данного фрагмента, нормы поведения, установки, правила и т.п.» [3, с. 18]. Иными словами, трансляция предполагает и обучение, а в качестве обучающих могут выступать представители «серебряного возраста», обладающие определёнными знаниями и опытом, в качестве обучающихся - все, кто желает перенять этот опыт, не обязательно младшее поколение.

Актуализация происходит с помощью механизмов ретрансляции наследия. Поэтому часто трансляцию называют одной из форм или одним из механизмов актуализации, то есть частью большого процесса воспроизведения и включения объектов наследия в актуальную культуру. В музеологии появляется новый термин «наследническая деятельность», который объединяет эти два понятия и понимается как «последовательный процесс сохранения, трансляции, аккумуляции и актуализации ценностей прошлого, прерывание которого ведёт к невосполнимым утратам» [4, с. 56].

Рассмотрим возможные формы трансляции культурного наследия в музее, предполагающие активное взаимодействие с людьми «серебряного возраста», условно выделив следующие: форма научно-экспозиционной интерпретации; форма культурно-образовательной деятельности; синтетическая форма вербально-визуальной трансляции; комплексная форма трансляции.

Далее обратимся к каждой из этих форм, проанализировав на примере конкретных музей- 
ных учреждений России. Так, форма научно-экспозиционной интерпретации музейных артефактов предполагает взаимодействие с людьми третьего возраста, которые могут выступать в качестве консультантов. Большой опыт консультативной помощи накоплен организаторами различных военно-исторических реконструкций, которые часто не имеют прямого отношения к музейным реконструкциям. Они давно и успешно привлекают к своей деятельности в качестве экспертов ветеранов и организации, объединяющие ветеранов, такие как «Российский Союз ветеранов» [5] и «Совет ветеранов ФСБ России» [6]. Связано это, прежде всего, с риском фальсификации и искажения исторических событий, участники которых могут помочь избежать в ходе создания реконструкций. Создавая музейные реконструкции бытовых интерьеров, мемориальных экспозиций, сотрудники также могут в качестве экспертов приглашать ветеранов и пенсионеров как свидетелей, которые могут уточнять детали, давать ценные рекомендации и консультации сотрудникам музеев в процессе актуализации и трансляции наследия.

Формы культурно-образовательной деятельности актуализируют нематериальное наследие в музее, а трансляция происходит напрямую от носителя новым поколениям (образовательные программы, экскурсии, музейные уроки, на которых живой «носитель традиции» представляет и передаёт свои идеи, знания и умения). В этом случае ввиду объективных причин (возраст прямых свидетелей культурных и исторических событий) носителями этого наследия и выступают люди «серебряного возраста», они воспроизводят нематериальное наследие в музее. «Музей обеспечивает людям, хранящим в памяти старинные песни и сказы, секреты мастерства, кулинарные рецепты и т. п., возможность деятельности, материальное обеспечение и ретрансляцию традиции через учеников. Действующие в музеях мастерские, фольклорные ансамбли, трактиры призваны не только сохранить навыки и традиции, но и передать опыт современникам и потомкам» [7]. Таким образом, музеи возрождают забытые промыслы и ремесла, а также конструируют и апробируют новые формы трансляции наследия, а представители третьего возраста, обладающие не только знаниями, но и конкретными навыками, могут быть участниками социально значимых процессов, способствующих укреплению межпоколенных связей. В данном случае именно они будут являться прямыми трансляторами нематериального культурного наследия.

«Рассматривая музей как хранителя уникальных памятников народного мастерства и традиций, музейщики видят ещё одну «лакуну» для пожилых посетителей музея - организация студий, школ народного мастерства, где народные умельцы делятся секретами мастерства и обучают желающих научиться вышивке, плетению, резьбе, ковке, лепке. Роль музея в приобщении пожилых посетителей к постижению корней и истоков традиционной культуры популярна не только в сельских регионах, богатых художественными промыслами. Горожане также с удовольствием собираются в музей и обучаются ткачеству, вышивке, лоскутному шитью и другим ремёслам. Весьма перспективным можно считать направление, где такие занятия проходят не по возрастному делению, а объединяют культурно-образовательный досуг семьи», - отмечает Е. Л. Галкина [8, с. 110-111]. Специалисты Дарвиновского музея, открывая в естественно-научном музее «школу ремёсел», по сути, добились эффективного решения трёх задач: актуализации и трансляции нематериального культурного наследия, налаживания межпоколенной коммуникации и ресоциализации людей «серебряного возраста». В такой школе сами мастера старшего поколения обучают своих сверстников ремеслу и передают свой опыт младшему поколению. «Создание такой воскресной школы может решить «проблему отцов и детей» через совместную деятельность: в неформальной обстановке старшие вновь станут примером для подражания, что позволит пенсионерам почувствовать себя вновь востребованными и успешными. Это может быть создание воскресного музея-мастерской, совместное изготовление сувенирной продукции и тому подобное» $[9$, с. 16].

Синтетическая форма вербально-визуальной трансляции предполагает работу как с объектами материального, так и с объектами нематериального наследия, выраженного в знаниях и воспоминаниях. Она включает в себя сбор и сохранение информации об объектах наследия, зафиксированных на разных носителях, а затем дальнейшую передачу, то есть трансляцию, этой информации в вербально-визуальной форме. Примером может быть акция по сбору блокадных и фронтовых артефактов, организованная Мемориальным музеем обороны и блокады Ленинграда и Музеем политической истории России в Санкт-Петербурге. Роль хранителя воспоминаний о военных годах взяла на себя Общественная организация «Дети блокады-900», она вела сбор докумен- 
тальных источников о войне [10]. На основе этих свидетельств была издана книга «Мгновения блокадного детства», состоящая из очерков, рассказов, стихотворений и фотографий, впоследствии переданная в школьный музей Невского района [11].

Еще один заслуживающий внимания пример - «Вичугский комплексный центр социального обслуживания населения». По его инициативе был осуществлен электронный проект «Музей воспоминаний», материалы которого впоследствии были переданы в краеведческий музей города Вичуга. За шесть месяцев реализации проекта с участием пожилых людей было записано 28 видеосюжетов, основой которых стали рассказы-воспоминания, записанные на видеокамеру [12]. В этом проекте помимо трансляции наследия, которая выражалась в передаче жизненного опыта младшим поколениям, решались также задача ресоциализации пожилых людей, которая состояла в стимулировании их жизненной активности. В проекте принял участие профессиональный психолог, который обеспечивал комфортные условия и оказывал психологическую помощь пожилому человеку при осуществлении видеозаписи порой тяжелых для него воспоминаний.

Комплексная форма трансляции отличается одновременным использованием всех каналов и способов трансляции наследия, доступных музею. Ярким примером комплексной формы может служить деятельность Музея истории профессионального образования в Москве. С первого года существования музея ветераны педагогического труда, ветераны войны и труда, труженики тыла полностью вовлечены в его работу. Они помогают в организации выставочной и экспозиционной работы, выступают в качестве экспертов в воспитательной деятельности. Совместно с ветеранами проводятся уроки мужества, дни воинской славы, смотры-конкурсы музеев профессиональных образовательных организаций, выставки творческих работ обучающихся и их наставников. При содействии ветеранов в музее развивается проектно-исследовательская деятельность ребят, наблюдается рост числа музейных программ, направленных на патриотическое воспитание и профессиональное образование [13].

Несмотря на то, что многочисленные примеры эффективной актуализации и трансляции наследия с участием пожилых людей нам дают различные культурные и социальные учреждения, а также общественные организации, музеи же только начинают осознавать свои возможности в этом направлении. Непосредственное участие пенсионеров в музейных мероприятиях в качестве трансляторов наследия, с одной стороны, способствует ресоциализации пожилых людей, показывая им важность и нужность, применимость и актуальность их личного опыта. С другой стороны, непосредственное взаимодействие музеев с людьми «серебряного возраста» как носителями культурного наследия оптимизирует межпоколенную коммуникацию, укрепляя социальные связи и придавая устойчивое развитие социуму в целом. Е. Л. Галкина в статье ««Забытый» посетитель» проанализировала творческие работы школьников, написанные на тему «Музей и люди пожилого возраста» в рамках проходившей в Москве VIII Всероссийской олимпиады по школьному краеведению. Участники попытались ответить на вопросы о том, что может дать музей пожилым людям и чем эта категория населения может быть полезна музею. Из наиболее интересных предложений авторов творческих работ исследователь выделила следующие: «Надо, чтобы во время экскурсий происходило взаимодействие этой категории посетителей с экспонатами - они могут лично показать, как использовать тот или иной предмет, как правильно носить костюм, как готовить пищу и т. д.». «Следует привлекать пожилых людей в роли экскурсоводов (волонтеров). В этой роли могли бы выступать знатоки краеведы, ветераны войны, собиратели коллекционеры, народные мастера, пенсионеры учителя и просто интересные люди. Это было бы здорово!» [8, с. 109-110]. Один из участников олимпиады предложил устраивать в музее «конкурсы и кружки мастеров, где пожилые люди могли бы не только показать свое мастерство, но и заработать - продать изделия в музейном магазине» [8, с. 109-110]. Очевидно, что молодое поколение заинтересовано в диалоге с пожилыми людьми, которые, по их мнению, могут выступать в качестве трансляторов наследия и экспертов в интерпретации музейных предметов и коллекций. Школьники нуждаются в этом общении, как и в приобретении знаний непосредственно от участников или свидетелей событий прошлого.

Итак, нельзя сказать, что в российских музеях не существует проектов по взаимодействию с людьми «серебряного возраста». Во многом их реализация обусловлена целенаправленной государственной политикой и пониманием того, что данная категория посетителей в музее есть и её 
нельзя не учитывать. Однако эти проекты пока не содержат такого мощного импульса развития и инновационных составляющих, как, например, проекты по работе с детской, подростковой аудиторией или с людьми с ограниченными возможностями здоровья. Анализ музейных программ и проектов по работе с людьми третьего возраста, в которых данная аудитория воспринимается не только как объект, но и как субъект взаимодействия, показывает, что в ресоциализации людей «серебряного возраста» музейные сотрудники используют в основном классические формы общения с пожилыми людьми и зачастую не обращаются к большому жизненному опыту и культурному багажу, которым обладают живые носители наследия. Для того чтобы способствовать развитию взаимодействия музеев с людьми «серебряного возраста», необходимо специально изучать интересы и учитывать потребности этой категории посетителей, разрабатывать инновационные методики взаимодействия с пожилыми людьми, привлекать к работе психологов и специалистов по геронтологии. Музейным специалистам следует обратиться к богатому опыту социальных и культурных учреждений, которые активно включены в работу с людьми третьего возраста. На основе его изучения необходимо создавать специальные проекты по привлечению аудитории пожилых людей к научному комплектованию музейных фондов, организации выставок, проведению широкого спектра мероприятий, сотрудничать со СМИ в целях поощрения людей «серебряного возраста» за вклад в музейную деятельность.

\section{Список литературы}

1. Словарь актуальных музейных терминов // Музей. - 2009. - № 5. - С. 47-68.

2. Овчинникова, 3. А. Роль музеев в формировании, поддержке и трансляции исторической и культурной памяти // Вестник Челябинской государственной академии культуры и искусств. - 2018. - № 1. C. 82-89.

3. Прокопенко, Ю.А. Сохранение и трансляция культурно-исторического наследия в СевероКавказском регионе : учеб. пособие. - Ставрополь : Изд-во СКФУ, 2017. - 270 с.

4. Курьянова, Т. С. Музей и нематериальное культурное наследие // Вестник Томского государственного университета. - 2012. - № 361. - С. 55-57.

5. О деятельности Санкт-Петербургского регионального отделения Общероссийской общественной организации ветеранов «Российский Союз ветеранов» в 2017 году // «Российский союз ветеранов», общер. обществ. орг-ия ветеранов : [офиц. сайт]. - Москва. - URL: http://soyuzveteranov.ru/content/o-deyatelnostisankt-peterburgskogo-regionalnogo-otdeleniya-obshcherossiyskoy (дата обращения: 19.12.2019).

6. Председатель Совета ветеранов ФСБ России Александр Жданьков: «Ветераны - это активная часть Службы» // «Жизнь Отечеству», электрон. вестник ветеран. и обществ. орг-ций Уральского фед. округа : [офиц. сайт]. - Екатеринбург. - URL: http://www.usprus.ru/component/k2/item/2319-predsedatel-sovetaveteranov-fsb-rossii-aleksandr-zhdankov-veterany-eto-aktivnaya-chast-sluzhby (дата обращения: 19.12.2019).

7. Нематериальное культурное наследие // Словарь музейных терминов Рос. музейной энциклопедии : [сайт].- Москва, 2002-2020. - URL: http://museum.ru/rme/dictionary.asp?31 (дата обращения: 19.12.2019).

8. Галкина, Е. «Забытый» посетитель // Музей и личность : сб. ст. / отв. ред. А.В.Лебедев. Москва : Рос. ин-т культурологии, 2007. - С. 101-116.

9. Клюкина, А. И. Социализация инвалидов музейными средствами // Творчество инвалидовнеограниченные возможности. Организация в музеях выставок инвалидов и адаптация выставок для восприятия людьми с ограничениями здоровья : матер. обучающего семинара (г. Москва, 18 окт. 2011 г.). Москва : ГДМ, 2011. - С. 5-22.

10. Лурикова, К. Своя война // Российская газета - Неделя: Северо-Запад : газета : [сайт]. - 2013. 3 окт. - URL: https://rg.ru/2013/10/03/reg-szfo/relikvii.html (дата обращения: 19.12.2019).

11. Представители союза «Дети блокады - 900» и глава администрации Невского района [г. СанктПетербурга, Россия] Константин Серов передадут книгу воспоминаний «Мгновения блокадного детства» в музеи ГБОУ СОШ Невского района // Офиц. сайт Администрации [города] Санкт-Петербурга [Российской Федерации] : [сайт]. - Санкт-Петербург, 2001-2020. - URL: https://www.gov.spb.ru/gov/terr/nevsky/news/ 61445/ (дата обращения: 19.12.2019).

12. «Музей воспоминаний» : [описание проекта] // Вичугский комплексный центр социального обслуживания населения, бюджет. уч-ие соц. обслуживания Ивановской обл. [Российской Федерации] : [сайт]. - Вичуга, 2014-2020. - URL: http://kcson-vichuga.ru/?page_id=3627 (дата обращения: 19.12.2019).

13. Калгашкина, В. Живой музей: незабываемые встречи // Учительская газета. - 2017. - 25 июля. URL: http://www.ug.ru/archive/70965 (дата обращения: 19.12.2019). 
Elena N. Mastenitsa,

Ph. D. in History, Associate Professor, Saint-Petersburg State Institute of Culture (Saint-Petersburg, Russia) elenamast@yandex.ru

\title{
MUSEUM INTER-GENERATIONAL COMMUNICATION IN PRESERVATION AND TRANSFERRING OF CULTURAL HERITAGE
}

\begin{abstract}
The paper gives a brief description of the key directions of work of a modern Russian museum with persons aged 60 years and above (retirement age); the segment of such visitors shows a stable dynamic growth in the total amount of museum public. Various role statuses of persons of the third age who act as participants of museum communication are named. The author analyses most popular forms of participation of retirement-aged persons in museum communication, such as: scientific museum exhibition, forms of cultural and educational activities, synthetic form of verbal and visual transferring, complex form of transferring of cultural heritage.

Key words: cultural heritage, a museum, cultural heritage in a museum, transferring cultural heritage in a тизеит культурного наследия в музее, a third-aged museum visitor, a museum visitor from late adulthood persons category, inter-generational museum communication, reintegration into society persons of retirement age by means of museum work.
\end{abstract}

УДК 130.2:316.73(4+5)

DOI 10.32340/2414-9101-2020-2-40-45

М. А. Носоченко, кандидат культурологии, доцент, Алтайский государственный институт культуры (Барнаул, Россия) caperucita.amarilla2016@gmail.com

\section{ВОСТОК - ЗАПАД: ПРОБЛЕМА ДИАЛОГА КУЛЬТУР}

Аннотация. Статья посвящена анализу сложной и длительной истории взаимоотношений Востока и Запада. Автор рассматривает некоторые аспекты развития восточной и западной интеллектуальных традиций в области логики, диалектики, гносеологии и теории сознания. Представлен сравнительный анализ принципов восточной (на примере Дхармакирти и Нагарджуны) и западной (на примере Аристотеля) логики, а также учений о душе и Эго-сознании. Цель работы показать, что подлинный диалог культур строится на поиске точек соприкосновения в интеллектуальной, художественной и религиозной сферах жизни общества без прямого заимствования чуждой системы ценностей. Такой диалог становится возможным при условии достижения культурами высокой степени зрелости, что проявляется, в частности, в осознании ими ограниченности собственных метафизических оснований. Полученные результаты свидетельствуют о преодолении Востоком изначально интровертной, а Западом - изначально экстарвертной - психической установки, что открывает возможности для конструктивного межкультурного диалога без риска утраты ими собственной идентичности.

Ключевые слова: философия, психология, теория культуры, логика, диалектика, феноменология, гносеология, теория сознания, Запад, Восток, диалог культур.

Теме диалога Востока и Запада посвящено большое количество исследований. Их сближение рассматривается как желанная цель многими философами, культурологами, социологами и политиками. Как интеллектуалы, так и обычные люди тянутся к духовному опыту Востока в надежде расширить горизонты собственного видения мира.

Однако в настоящее время всё громче звучат голоса тех, кто высказывает сомнение в перспективах полноценного диалога Востока и Запада, а также в возможностях понимания восточной духовности западным человеком. 